\title{
The Influence of Oxygen Saturation on the Relationship Between Hemoglobin Mass and $\mathrm{VO}_{2}$ max
}

\section{(ㄷ)(ㄱ)(오 $\Theta$}

Authors

Jesse A. Goodrich, Benjamin J. Ryan, William C. Byrnes

\section{Affiliations}

Department of Integrative Physiology, University of Colorado Boulder, Boulder, United States

\section{Key words}

endurance performance, oxygen transport, exercise-induced desaturation, hypoxia, altitude

received 12.02 .2018

revised 11.05 .2018

accepted 05.06.2018

\section{Bibliography}

DOI https://doi.org/10.1055/a-0655-7207

Sports Medicine International Open 2018; 2: E98-E104

(c) Georg Thieme Verlag KG Stuttgart · New York

ISSN 2367-1890

\section{Correspondence}

Mr. Jesse A Goodrich,

Department of Integrative Physiology

University of Colorado Boulder

1725 Pleasant St.

Boulder, 80309

United States

Tel.: + 1/303/735 0358, Fax: + 1/303/492 4009

jesse.goodrich@colorado.edu

\begin{abstract}
Hemoglobin mass (tHb) is a key determinant of maximal oxygen uptake $\left(\mathrm{VO}_{2} \mathrm{max}\right)$. We examined whether oxyhemoglobin desaturation $\left(\Delta \mathrm{S}_{\mathrm{a}} \mathrm{O}_{2}\right)$ at $\mathrm{VO}_{2}$ max modifies the relationship between $\mathrm{tHb}$ and $\mathrm{VO}_{2}$ max at moderate altitude $(1,625 \mathrm{~m})$. Seventeen female and 16 male competitive, endurance-trained moderate-altitude residents performed two tHb assessments and two graded exercise tests on a cycle ergometer to determine $\mathrm{VO}_{2}$ max and $\Delta \mathrm{S}_{\mathrm{a}} \mathrm{O}_{2}$. In males and females respectively, $\mathrm{VO}_{2} \max \left(\mathrm{ml} \cdot \mathrm{kg}^{-1} \cdot \mathrm{min}^{-1}\right)$ ranged from $62.5-83.0$ and $44.5-$ $67.3 ; \mathrm{tHb}\left(\mathrm{g} \cdot \mathrm{kg}^{-1}\right)$ ranged from $12.1-17.5$ and 9.1-13.0; and $\mathrm{S}_{\mathrm{a}} \mathrm{O}_{2}$ at $\mathrm{VO}_{2} \max (\%)$ ranged from 81.7-94.0 and 85.7-95.0. tHb was related to $\mathrm{VO}_{2}$ max when expressed in absolute terms and after correcting for body mass ( $r=0.94$ and 0.86 , respectively); correcting by $\Delta \mathrm{S}_{a} \mathrm{O}_{2}$ did not improve these relationships $(r=0.93$ and 0.83$)$. Additionally, there was a negative relationship between tHb and $\mathrm{S}_{\mathrm{a}} \mathrm{O}_{2}$ at $\mathrm{VO}_{2} \max (r=-0.57)$. In conclusion, across a range of endurance athletes at moderate altitude, the relationship between $\mathrm{tHb}$ and $\mathrm{VO}_{2}$ max was found to be similar to that observed at sea level. However, correcting $\mathrm{tHb}$ by $\Delta \mathrm{S}_{\mathrm{a}} \mathrm{O}_{2}$ did not explain additional variability in $\mathrm{VO}_{2}$ max despite significant variability in $\Delta \mathrm{S}_{\mathrm{a}} \mathrm{O}_{2}$; this raises the possibility that $\mathrm{tHb}$ and exercise-induced $\Delta \mathrm{S}_{\mathrm{a}} \mathrm{O}_{2}$ are not independent in endurance athletes.
\end{abstract}

\section{Introduction}

$\mathrm{VO}_{2}$ max is a critical factor for endurance exercise performance because it sets the upper limit for aerobic metabolism $[1,19,20]$. The primary limitation of $\mathrm{VO}_{2} \mathrm{max}$ is the rate of oxygen delivery to the working muscle [1, 24]; many physiological parameters that influence oxygen delivery during exercise have been described previously $[1,20,23]$.

One parameter that influences $\mathrm{VO}_{2}$ max is the total mass of hemoglobin in circulation ( $\mathrm{tHb}$ ) [35]. tHb influences $\mathrm{VO}_{2}$ max both via its relationship with hemoglobin concentration ([Hb]) and arterial oxygen content $\left(\mathrm{C}_{\mathrm{a}} \mathrm{O}_{2}\right)$ [35], and via its relationship with total blood volume, venous return and ventricular filling, and maximal cardiac output $[10,18,21,35]$. However, tHb and [Hb] are not the only factors that influence $\mathrm{C}_{\mathrm{a}} \mathrm{O}_{2}$; arterial oxygen partial pressure and arterial oxygen saturation $\left(\mathrm{S}_{a} \mathrm{O}_{2}\right)$ also influence $\mathrm{C}_{a} \mathrm{O}_{2}$. During high-intensity exercise, $\mathrm{S}_{\mathrm{a}} \mathrm{O}_{2}$ can drop significantly in a variety of athletes; this condition is known as exercise-induced arterial desaturation (EIAD). When EIAD was initially described in the literature, it was thought that decreased arterial oxyhemoglobin concentration during exercise led to decreased $\mathrm{C}_{a} \mathrm{O}_{2}$. However, highintensity exercise increases arterial blood temperature and can lead to plasma volume shifts and hemoconcentration; in individuals that do not experience EIAD, these changes can lead to an increase in $\mathrm{C}_{\mathrm{a}} \mathrm{O}_{2}$ during high-intensity exercise [36], and therefore EIAD may simply prevent an increase in $\mathrm{C}_{\mathrm{a}} \mathrm{O}_{2}$ during high intensity [15]. Regardless, it is clear that EIAD has a detrimental effect on $\mathrm{VO}_{2} \mathrm{max}$, because ameliorating EIAD by increasing the fraction of inspired 
oxygen from $21 \%$ to $26 \%$ leads to an increase in $\mathrm{VO}_{2}$ max only in individuals with EIAD [15].

At sea level, EIAD is uncommon in recreationally active subjects, but $\sim 50 \%$ of elite endurance athletes experience some degree of EIAD [25]. As altitude increases, EIAD is exacerbated in all individuals [22]. There is also significant interindividual variability in the severity of EIAD experienced during exercise, even within groups of similarly trained athletes $[12,26]$. Therefore, assuming EIAD and tHb are independent, EIAD may influence the relationship between tHb and $\mathrm{VO}_{2}$ max.

Although $\mathrm{tHb}$ and EIAD both influence oxygen delivery during exercise, to date there have been no studies looking at how these factors interact to influence $\mathrm{VO}_{2}$ max. Therefore, the purpose of this study was to determine whether EIAD influences the relationship between $\mathrm{tHb}$ and $\mathrm{VO}_{2}$ max in moderately to highly trained competitive male and female endurance athletes at moderate altitude (1,625 meters). Additionally, previous research has indicated that females may be more likely to experience EIAD than males due to anatomical differences [8,9]. However, direct comparisons of EIAD between competitive, endurance-trained male and female athletes are lacking. Therefore, a secondary aim of this study was to compare severity of EIAD at moderate altitude in men and women after taking into account aerobic capacity.

\section{Methods}

\section{Subjects}

Seventeen female and sixteen male competitive endurance-trained cyclists and triathletes residing at moderate altitude $(1,500-$ 2,000 meters) took part in this study. Subjects were required to maintain moderate-altitude residence throughout participation in the study, and testing occurred at 1,625 meters. Endurance-trained was defined as cycling, running, and/or swimming for more than $10 \mathrm{~h}$ per week for men and more than $8 \mathrm{~h}$ per week for women over the month prior to inclusion in the study. All subjects had participated in at least one discipline-specific competitive race in the previous calendar year. At the time of the first visit, males were required to hold at a minimum a USA Cycling Category 2 or USA triathlon license; females were required to hold at a minimum a USA Cycling Category 3 or USA triathlon license. Subjects were screened to ensure that they were between the ages of 18-42 years old, free from known cardio-respiratory disease as assessed by the Physical Activity Readiness Questionnaire (PAR-Q), had not donated blood in the previous 8 weeks, and were non-smokers. Subjects were not excluded from the study if they had participated in short sojourns to sea level ( $<7$ days) in the 8 weeks prior to participation in the study, because hemoglobin mass has previously been shown to be stable for up to two weeks following descent to sea level in endurance-trained moderate-altitude residents [28]. Females were screened to ensure they were not pregnant or breast feeding, and all females undertook a urine hCG test prior to participating (AccuMed, USA).

\section{Experimental design}

Because duplicate measurements reduce the typical error of a measurement by $\sqrt{2}$ [17], measurements of all primary outcomes (tHb,
$\mathrm{VO}_{2}$ max, and $\mathrm{S}_{\mathrm{a}} \mathrm{O}_{2}$ ) were performed twice. On the first of four visits to the lab, written informed consent was obtained. In order to confirm that there were no changes in tHb throughout the study, visits one and four consisted of identical measurements of $\mathrm{tHb}$, whereas visits two and three consisted of identical graded exercise tests (GXT) to measure maximal oxygen uptake and $\mathrm{S}_{\mathrm{a}} \mathrm{O}_{2}$ during exercise. All visits were separated by at least one day, and for each subject, GXTs were performed at the same time of day, plus or minus one hour. This study was conducted in accordance with the ethical standards of the International Journal of Sports Medicine [16].

\section{Total hemoglobin mass}

Total hemoglobin mass was measured via the optimized carbon monoxide rebreathing procedure $[27,34]$ as described previously $[32,33]$. Subjects were instructed to refrain from exercise for two hours preceding these visits due to the possible interactions between exercise and carboxyhemoglobin kinetics. For this study, the coefficient of variability was $2.7 \%$ (95\% confidence interval: $2.2 \%$ $3.7 \%)$.

\section{Graded exercise test}

On visits two and three, subjects performed a maximal GXT on a cycle ergometer (Lode Excalibur Sport, Groningen, Netherlands). For these visits, subjects were instructed to arrive at the lab two hours postprandial, and were instructed to not consume alcohol or perform vigorous activity for $24 \mathrm{~h}$ prior to either GXT. Prior to the GXT, body mass was measured on a digital scale (Combics 1 , Sartorius Weighing Technology, Göttingen, Germany) in cycling clothes and without shoes. Oxygen consumption and other metabolic parameters were measured via computerized open-circuit indirect calorimetry, which was calibrated according to the manufacturer's specifications (TrueOne 2400, Parvo Medics, Sandy, UT, USA). Heart rate was measured using a heart rate monitor (Polar Electro, Kempele, Finland), and peripheral oxygen saturation was measured continuously via forehead pulse oximetry (Nellcor N-595, Medtronic, Minneapolis, MN, USA). Forehead pulse oximetry was chosen due to its ability to determine $\mathrm{S}_{\mathrm{a}} \mathrm{O}_{2}$ with relatively low bias and high precision compared to other non-invasive measurement options [37]. After five minutes of rest on the ergometer, baseline $\mathrm{S}_{\mathrm{a}} \mathrm{O}_{2}$ was measured for one minute. Each subject was then allowed a 10-min warm-up period during which the subject rode at a selfselected power not exceeding the power output of the first stage of the GXT. Following the warm-up period, the subject put on a nose clip and began breathing through the open-circuit spirometry system. The GXT began at an individualized power output of $4 \mathrm{~W} \cdot \mathrm{kg}^{-1}$ for males and $3 \mathrm{~W} \cdot \mathrm{kg}^{-1}$ for females, rounded down to the nearest $20 \mathrm{~W}$ increment, and increased $20 \mathrm{~W}$ every minute until subjects reached volitional exhaustion or until cadence could not be maintained above 60 RPM. This sex-specific protocol was used in order to elicit volitional exhaustion in this subject population in about 10-12 min, which has been reported to be an optimal duration for determining $\mathrm{VO}_{2}$ max [4]. During each GXT, all subjects reached an $\mathrm{RPE}>17$ and a $\mathrm{HR}_{\max }$ within $10 \%$ of age-predicted $\mathrm{HR}_{\max }$. As previously described, $\mathrm{VO}_{2}$ max was calculated as the highest 30-s average oxygen consumption; $\mathrm{S}_{\mathrm{a}} \mathrm{O}_{2}$ at $\mathrm{VO}_{2}$ max was calculated as the average $\mathrm{S}_{\mathrm{a}} \mathrm{O}_{2}$ during the same $30 \mathrm{~s}$ used to determine 
$\mathrm{VO}_{2} \max [3,32]$. Peak power output was calculated as described previously using the following equation [3, 32]:

Peak power output $=$ penultimate - stage power output

+ (power increase between stages

$\times$ (seconds into the final stage/60 seconds))

Mild, moderate, and severe EIAD were classified as a $\mathrm{S}_{\mathrm{a}} \mathrm{O}_{2}$ at $\mathrm{VO}_{2}$ max between $93-95 \%, 88-93 \%$, and $<88 \%$, respectively [7]. The coefficients of variation for $\mathrm{VO}_{2}$ max and $\mathrm{S}_{\mathrm{a}} \mathrm{O}_{2}$ at $\mathrm{VO}_{2}$ max using these duplicate measurements were $3.5 \%$ (95\% confidence interval: 2.8 $4.7 \%$ ) and $1.4 \%$ (95\% confidence interval: $1.2-1.8 \%$ ), respectively.

\section{Saturation-adjusted tHb}

To determine how saturation influences the relationship between $\mathrm{tHb}$ and $\mathrm{VO}_{2}$ max, saturation-adjusted $\mathrm{tHb}$ was calculated as satadj $\mathrm{tHb}=\mathrm{tHb} \cdot\left(\mathrm{S}_{a} \mathrm{O}_{2}\right.$ at $\left.\mathrm{VO}_{2} \mathrm{max}\right)$.

\section{Statistics}

To determine if there were differences between duplicate tests, dependent t-tests were used to compare measurements. In order to determine the degree of agreement between duplicate measurements, intraclass correlation coefficients were calculated; to assess the typical error of duplicate measurements, the coefficient of variation was calculated as a percent change [17]. To determine the relationship between $\mathrm{tHb}$ and $\mathrm{VO}_{2} \mathrm{max}$, as well as the relationship between saturation-adjusted $\mathrm{t} \mathrm{Hb}$ and $\mathrm{VO}_{2} \mathrm{max}$, simple linear regressions were performed. Linear regression models were compared using Williams t-test. To assess differences in $\mathrm{S}_{\mathrm{a}} \mathrm{O}_{2}$ at $\mathrm{VO}_{2} \mathrm{max}$ between sexes, multiple linear regression was performed with sex and $\mathrm{VO}_{2}$ max as independent variables and $\mathrm{S}_{\mathrm{a}} \mathrm{O}_{2}$ at $\mathrm{VO}_{2}$ max as the dependent variable. For all regression analyses, bivariate normality was assessed using Q-Q plots and Shapiro-Wilk tests on the residuals, homoscedasticity and linearity were assessed using scatter plots of normalized residuals, and autocorrelation was assessed using the Box-Pierce test. Unstandardized regression coefficients from linear models are reported using the symbol $\beta$. All analyses were performed in R, version 3.3.2 (R Core Team, Vienna, Austria), and alpha was set to 0.05 . Trends were noted if $0.05<p<0.1$. Results are represented as the mean \pm SD.

\section{Results}

Subject characteristics and measures of reliability between duplicate measures are given in $>$ Table $\mathbf{1}$. Of the 33 subjects who participated, 32 completed all experimental procedures; one female subject was withdrawn due to illness after completing the first two visits, so her results represent only a single measurement of each parameter.

There were no significant differences between tests for the following measures: $\mathrm{tHb}$, body mass, $\mathrm{S}_{\mathrm{a}} \mathrm{O}_{2}$ at rest, $\mathrm{S}_{\mathrm{a}} \mathrm{O}_{2}$ at $\mathrm{VO}_{2}$ max, desaturation from rest, maximum heart rate, maximum RER, peak power output, and maximum RPE (all $p=N$.S.). $\mathrm{VO}_{2}$ max was significantly higher for the second GXT, both when expressed as $\mathrm{L} \cdot \mathrm{min}^{-1}$ (delta $=0.064 \mathrm{~L} \cdot \mathrm{min}^{-1}, \mathrm{p}=0.048$ ) and when expressed as $\mathrm{mL} \cdot \mathrm{min}^{-1} \cdot \mathrm{kg}^{-1}\left(\right.$ delta $\left.=1.21 \mathrm{~mL} \cdot \mathrm{min}^{-1} \cdot \mathrm{kg}^{-1}, \mathrm{p}=0.02\right)$. The change in $\mathrm{VO}_{2}$ max between trials was not different between males and females $(p=N . S$.). Although there was no significant difference in peak power output between tests, the difference in $\mathrm{VO}_{2}$ max between tests was related to the difference in peak power output $\left(p<0.001, r^{2}=0.44\right)$, which indicates that there may have been a learning effect that took place between GXTs. The magnitude of the difference in $\mathrm{VO}_{2}$ max between tests was small ( $<2 \%$ ). To examine whether this difference influenced our conclusions, all fur-

- Table 1 Subject Characteristics and Measurement Variability.

\begin{tabular}{|c|c|c|c|c|}
\hline & Male $n=16$ & Female $n=17$ & $\begin{array}{l}\text { Coefficient of } \\
\text { variation (\%) }\end{array}$ & $\begin{array}{c}\text { Intra-class correlation } \\
\text { coefficient }\end{array}$ \\
\hline Age & $25.6 \pm 4.6$ & $28.6 \pm 6.0$ & - & - \\
\hline Weekly Training Duration (hours) & $16.3 \pm 5.4$ (Range: $10-30)$ & $13.5 \pm 4.1$ (Range: $8.2-25$ ) & - & - \\
\hline Body Mass (kg) & $69.7 \pm 4.8$ & $58.4 \pm 5.1$ & 0.8 & 0.99 \\
\hline Height $(\mathrm{cm})$ & $182.1 \pm 4.1$ & $165.5 \pm 5.1$ & - & - \\
\hline Absolute $\mathrm{VO}_{2} \max \left(\mathrm{L} \cdot \mathrm{min}^{-1}\right)$ & $5.12 \pm 0.45$ & $3.22 \pm 0.43$ & 3.5 & 0.99 \\
\hline Normalized $\mathrm{VO}_{2} \max \left(\mathrm{mL} \cdot \mathrm{kg}^{-1} \cdot \mathrm{min}^{-1}\right)$ & $73.4 \pm 5.4$ & $55.2 \pm 5.9$ & 3.5 & 0.96 \\
\hline $\mathrm{RER}$ at $\mathrm{VO}_{2} \max$ & $1.05 \pm 0.05$ & $1.07 \pm 0.06$ & 1.4 & 0.86 \\
\hline HR max & $184 \pm 9$ & $185 \pm 11$ & 2.0 & 0.85 \\
\hline Peak Power Output (W) & $429 \pm 26$ & $292 \pm 31$ & 2.4 & 0.99 \\
\hline $\mathrm{S}_{\mathrm{a}} \mathrm{O}_{2}$ at Rest $(\%)$ & $98.18 \pm 0.94$ & $98.86 \pm 0.87$ & 0.8 & 0.49 \\
\hline $\mathrm{S}_{\mathrm{a}} \mathrm{O}_{2}$ at $\mathrm{VO}_{2} \max (\%)$ & $88.8 \pm 3.1$ & $92.0 \pm 2.8$ & 1.4 & 0.86 \\
\hline Desaturation from Rest (\%) & $9.1 \pm 3.5$ & $6.9 \pm 2.6$ & 16.1 & 0.84 \\
\hline Absolute tHb (g) & $977 \pm 102$ & $647 \pm 100$ & 2.7 & 0.99 \\
\hline Normalized tHb $\left(\mathrm{g} \cdot \mathrm{kg}^{-1}\right)$ & $14.0 \pm 1.3$ & $11.1 \pm 1.3$ & 2.7 & 0.99 \\
\hline \multicolumn{5}{|c|}{$\begin{array}{l}\text { Values are mean } \pm \mathrm{SD} \text {. } \mathrm{VO}_{2} \text { max: Maximal oxygen uptake during graded exercise test; RER: Respiratory exchange ratio; } \mathrm{HR} \text { max: maximum heart rate } \\
\text { during graded exercise test; Peak Power Output: peak power output during graded exercise test; } \mathrm{S}_{\mathrm{a}} \mathrm{O}_{2} \text { : arterial oxyhemoglobin saturation; tHb: total } \\
\text { hemoglobin mass. Weekly training duration was calculated from self-reported hours of endurance training per week over the month preceding } \\
\text { inclusion in study. } \mathrm{H} \mathrm{Hb} \text { parameters are the average of two measurements, whereas all graded exercise test parameters }\left(\mathrm{VO}_{2} \text { max, } \mathrm{RER} \text { at } \mathrm{VO}_{2} \text { max, } \mathrm{HR}\right. \\
\text { max, Peak Power Output, } \mathrm{S}_{\mathrm{a}} \mathrm{O}_{2} \text { at } \mathrm{VO}_{2} \mathrm{max} \text {, and Desaturation from Rest) are taken from the } 2^{\text {nd }} \text { graded exercise test, because } \mathrm{VO}_{2} \text { max was signifi- } \\
\text { cantly higher for this test. }\end{array}$} \\
\hline
\end{tabular}


ther analyses were performed twice, once using results from the average of both GXTs, and once using results from only the second GXT. There were no differences in any conclusion regardless of which variables were used, and therefore all results are presented from the second GXT, including $\mathrm{VO}_{2}$ max, $\mathrm{S}_{\mathrm{a}} \mathrm{O}_{2}$ at $\mathrm{VO}_{2}$ max, peak RER, and peak power output.

\section{Exercise-induced arterial desaturation}

At $\mathrm{VO}_{2}$ max, the average desaturation from rest was $9.1 \pm 3.5 \%$ for males and $6.9 \pm 2.6 \%$ for females. In males, $\mathrm{S}_{\mathrm{a}} \mathrm{O}_{2}$ at $\mathrm{VO}_{2}$ max ranged from $81.7 \%$ to $94.0 \%$; in females $\mathrm{S}_{\mathrm{a}} \mathrm{O}_{2}$ at $\mathrm{VO}_{2}$ max ranged from $85.7 \%$ to $95 \%$. Overall, $94 \%$ of subjects experienced greater than $4 \%$ desaturation from rest (95\% confidence interval: $80 \%-99 \%$ ), with no statistical difference between men and women ( $\triangleright$ Table 2). $\mathrm{S}_{\mathrm{a}} \mathrm{O}_{2}$ at $\mathrm{VO}_{2}$ max was negatively related to $\mathrm{VO}_{2}$ max, both when expressed as an absolute $(r=-0.58, p<0.001)$ and when normalized to body mass $(r=-0.55, p<0.001)$. When split by sex, this relationship was observed only in the female cohort (for females, absolute: $r=-0.59$, $p<0.05$; normalized: $r=-0.62, p<0.05)$. There was no significant difference in the severity of EIAD between males and females after accounting for $\mathrm{VO}_{2} \max (p=N$.S.).

\section{Relationship between $\mathrm{tHb}$ and $\mathrm{VO}_{2} \max$}

tHb was positively related to $\mathrm{VO}_{2}$ max when both parameters were expressed as absolute values $\left(\beta_{\mathrm{tHb}}=5.07 ; r^{2}=0.88, p<0.001 ;>\right.$ Fig. 1a)

- Table 2 Prevalence of Exercise-induced Arterial Desaturation.

\begin{tabular}{|c|c|c|}
\hline EIAD Severity & Male (\%) n= 16 & Female $(\%) n=17$ \\
\hline Mild & $12.5[1-38]$ & $24[7-50]$ \\
\hline Moderate & $50[25-75]$ & 53 [28-77] \\
\hline Severe & 38 [15-65] & $12[1-36]$ \\
\hline Overall & $100[79-100]$ & 88 [64-99] \\
\hline \multicolumn{3}{|c|}{$\begin{array}{l}\text { Values are presented as percent [ } 95 \% \text { confidence interval]. EIAD: } \\
\text { exercise-induced arterial desaturation. Mild, moderate, and severe } \\
\text { EIAD were classified as an } \mathrm{S}_{\mathrm{a}} \mathrm{O}_{2} \text { at } \mathrm{VO}_{2} \text { max between } 93-95 \% \text {, } \\
88-93 \% \text {, and }<88 \% \text {, respectively [3]. }\end{array}$} \\
\hline
\end{tabular}

and when both parameters were normalized to body mass $\left(\beta_{\mathrm{tHb}}=4.70 ; r^{2}=0.73, p<0.001 ;>\right.$ Fig. 2a). When split by sex, the magnitude of the correlation decreased, but similar relationships were observed in both males (absolute: $r^{2}=0.44, p<0.01$; normalized: $r^{2}=0.32, p=0.02$ ) and in females (absolute: $r^{2}=0.67, p<0.01$; normalized: $\left.r^{2}=0.42, p<0.01\right)$.

\section{Saturation-adjusted t $\mathrm{Hb}$}

When tHb was adjusted by $\mathrm{S}_{\mathrm{a}} \mathrm{O}_{2}$ at $\mathrm{VO}_{2}$ max, this parameter was positively related to $\mathrm{VO}_{2}$ max, both when expressed as absolute values $\left(\beta=6.05 ; r^{2}=0.87, p<0.001 ;>\right.$ Fig. 1b) and when normalized to body mass $\left(\beta=5.65 ; r^{2}=0.68, p<0.01\right.$; Fig. 2b). When compared to the model between $\mathrm{tHb}$ and $\mathrm{VO}_{2} \mathrm{max}$, there was no significant difference between the amounts of explained variability, either for the absolute ( $p=$ N.S.; $>$ Fig. 1) or for the body mass normalized models ( $p=$ N.S.; Fig. 2 ).

\section{thb and $\mathrm{S}_{\mathrm{a}} \mathrm{O}_{2}$ at $\mathrm{VO}_{2} \mathrm{max}$}

Across all subjects, when tHb was normalized by body mass, it was negatively related to $\mathrm{S}_{a} \mathrm{O}_{2}$ at maximal exercise $\left(r^{2}=0.32, p<0.001\right.$; - Fig. 3). When split by sex, there was a trend for this relationship to show up in females $\left(r^{2}=0.22, p=0.06\right)$ but not males $\left(r^{2}=0.06\right.$, $p=N . S$.). After diagnostic testing of this model, this analysis was re-run after removing one male subject who exerted a high degree of influence on the original model. In the reduced data set, there was still a significant relationship between $\mathrm{tHb}$ and $\mathrm{S}_{\mathrm{a}} \mathrm{O}_{2}$ at $\mathrm{VO}_{2}$ max $\left(r^{2}=0.202, p=0.01\right)$. A secondary analysis of this data revealed that when only subjects who experienced an $\mathrm{S}_{\mathrm{a}} \mathrm{O}_{2}$ at $\mathrm{VO}_{2}$ max less than $91 \%$ were analyzed (which included 15 subjects), $r^{2}$ increased from 0.32 to 0.48 ( $<<0.01$ for this model).

\section{Discussion}

The primary findings from this study are that 1 ) adjusting thb by $\mathrm{S}_{\mathrm{a}} \mathrm{O}_{2}$ at $\mathrm{VO}_{2}$ max did not improve the amount of explained variability in $\mathrm{VO}_{2} \mathrm{max}$, and 2) after correcting for aerobic capacity, there was no difference in severity of EIAD between males and females.

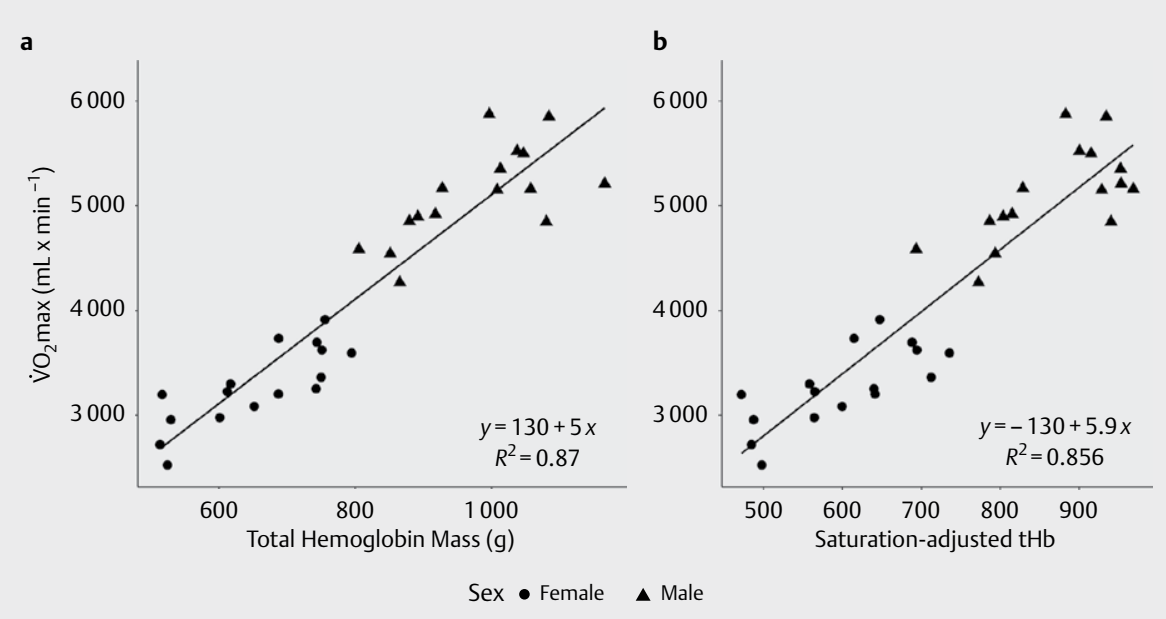

- Fig. 1 Relationship between $\mathrm{VO}_{2}$ max and a absolute total hemoglobin mass (tHb); $\mathbf{b}$ total hemoglobin mass adjusted by arterial oxygen saturation during maximal aerobic exercise, without taking into account body mass. No significant difference was found between regressions ( $p=N$.S.). 


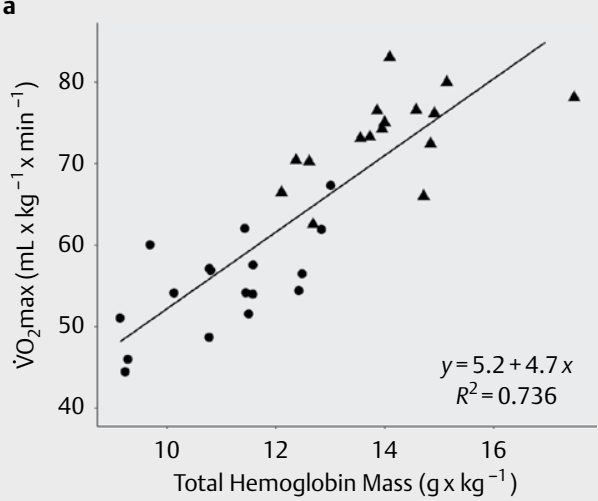

Sex • Female b

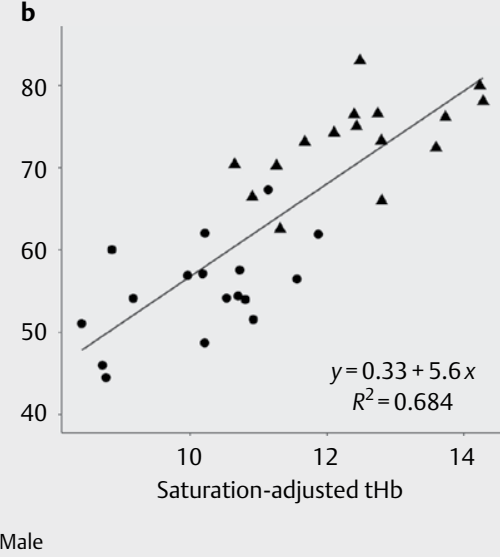

Fig. 2 Relationship between $\mathrm{VO}_{2}$ max normalized by body mass and a body mass-normalized total hemoglobin mass (tHb); $\mathbf{b}$ total hemoglobin mass adjusted by arterial oxygen saturation during maximal aerobic exercise, after normalizing by body mass. No significant difference was found between regressions ( $p=$ N.S.).

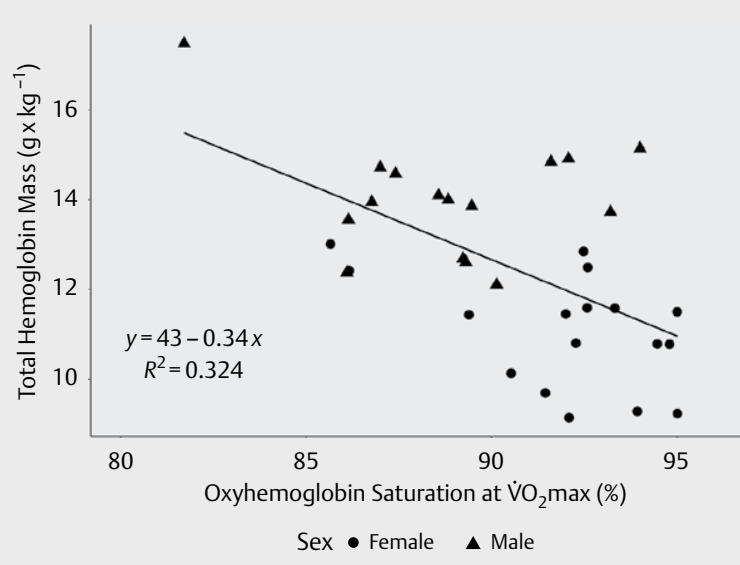

-Fig. 3 Relationship between $\mathrm{S}_{\mathrm{a}} \mathrm{O}_{2}$ at $\mathrm{VO}_{2}$ max and total hemoglobin mass $\left(r^{2}=0.324, p<0.001\right)$.

Additionally, we found that $\mathrm{tHb}$ was negatively related to $\mathrm{S}_{\mathrm{a}} \mathrm{O}_{2}$ at $\mathrm{VO}_{2}$ max.

The finding that $\mathrm{S}_{\mathrm{a}} \mathrm{O}_{2}$ at $\mathrm{VO}_{2}$ max did not explain additional variability in the relationship between $\mathrm{tHb}$ and $\mathrm{VO}_{2}$ max was contrary to our hypothesis. This was despite a high prevalence of EIAD and a large range of observed desaturation values in this cohort. If $\mathrm{tHb}$ and $\mathrm{S}_{\mathrm{a}} \mathrm{O}_{2}$ at $\mathrm{VO}_{2}$ max were both independent predictors of $\mathrm{VO}_{2}$ max, it would be expected that the relationship between $\mathrm{tHb}$ and $\mathrm{VO}_{2}$ max would improve after taking into account $\mathrm{S}_{\mathrm{a}} \mathrm{O}_{2}$ at $\mathrm{VO}_{2}$ max. However, accounting for $\mathrm{S}_{\mathrm{a}} \mathrm{O}_{2}$ at $\mathrm{VO}_{2}$ max resulted in no significant changes in the relationship between these variables, which indicates that $\mathrm{tHb}$ and EIAD may not be independent. This concept is supported by our finding that $\mathrm{S}_{\mathrm{a}} \mathrm{O}_{2}$ at $\mathrm{VO}_{2}$ max was negatively correlated to tHb ( $\vee$ Fig. 3 ). Although we do not have direct evidence to explain these results, there are two possible physiological explanations. One possibility is that individuals with high tHb may expe- rience more severe desaturation during exercise due to the presence of high blood volume. High blood volume enables greater venous return and ventricular filling, and is therefore a prerequisite for high cardiac output; however, as cardiac output increases, pulmonary capillary transit time decreases, which is believed to be one of the predominate factors leading to exercise-induced hypoxemia and desaturation in athletes [6,31].

Another possible explanation for this finding is that desaturation during exercise may influence the regulation of $\mathrm{tHb}$. It is well documented that hypoxia can augment erythropoiesis and increase tHb [13]. Although very little research has been performed to directly study this issue, previous research indicates that hypoxemia during high-intensity exercise may interact with environmental hypoxia to create a larger erythropoietic stimulus in individuals who experience more severe EIAD. For example, in athletes with $\mathrm{S}_{\mathrm{a}} \mathrm{O}_{2}$ at $\mathrm{VO}_{2}$ max below $91 \%$, three minutes of maximal aerobic exercise at sea level was found to elevate serum erythropoietin (EPO) for at least $24 \mathrm{~h}$ following exercise, and were found to increase reticulocyte count $96 \mathrm{~h}$ following exercise, whereas individuals with $\mathrm{S}_{\mathrm{a}} \mathrm{O}_{2}$ at $\mathrm{VO}_{2}$ max above $91 \%$ had no significant change in EPO or reticulocytes over time [29]. Additional research by the same group found that the increase in circulating EPO $24 \mathrm{~h}$ following high-intensity exercise was $\sim 50 \%$ higher when the exercise was performed in simulated normobaric hypoxia (2,100 meters compared to 1,000 meters) [30]. This finding was hypothesized to be a function of the significantly lower $\mathrm{S}_{a} \mathrm{O}_{2}$ during exercise in the simulated hypoxia compared to the control condition. To our knowledge, only one study has followed up on these results to examine whether highintensity exercise performed in hypoxia can augment increases in hemoglobin mass over time compared to the equivalent training in normoxia. Brocherie et al. reported that 6 bouts of sprint interval training performed in hypoxia throughout a two-week live-high/ train-low training camp increased thb by $4 \%$ on average, compared to a control group that lived high but performed sprint interval training in normoxia, which increased tHb only by $2.8 \%$ (although these were not statistically different, in part due to low sample size) 
[2]. Taken together, these results raise the possibility that individual variability in EIAD severity during exercise may be one factor that influences $\mathrm{tH}$ in endurance athletes, especially over long durations of time or in athletes residing at moderate altitude. However, we do not have direct evidence to support this hypothesis, and therefore further experimental research is required to fully elucidate the relationship between EIAD and tHb.

Our finding that there was no difference in severity or prevalence of EIAD at moderate altitude between endurance-trained males and females is in contrast to our hypothesis. Previous work has identified that females experience more severe mechanical respiratory constraints during exercise compared to males $[8,14]$, which can exacerbate EIAD and has led to the hypothesis that females may be more likely than males to exhibit EIAD [5]. Our findings do not support this hypothesis. Our lab has previously published similar findings in endurance-trained male and female cyclists, where we reported no significant difference between males and females in $\mathrm{S}_{\mathrm{a}} \mathrm{O}_{2}$ at $\mathrm{VO}_{2}$ max at moderate altitude [3]. Interestingly, this study did find a statistically significant difference in the degree of desaturation in males versus females, but it was males, not females, that exhibited larger desaturation. One important caveat to this previous finding is that the statistical tests used for these comparisons did not take into account aerobic capacity, which is known to be a confounding variable for EIAD [5, 7, 8]. Taken together with previous work in this area, our findings seem to indicate that although females may generally have respiratory anatomy that increases susceptibility to EIAD, the severity of this phenomenon depends upon a complex interplay of several physiological, anatomical, and environmental (i. e., altitude) factors, some of which seem to be of different importance in males versus females.

One strength of this study was that we were able to examine a relatively large sample of both male and female endurance athletes across a range of abilities. This can help to explain the finding that $\mathrm{VO}_{2}$ max increased between GXTs. This finding is not unprecedented; for example, Edgett et al. recently analyzed the reliability of $\mathrm{VO}_{2}$ max measured over three GXTs performed on a cycle ergometer in 45 recreationally active adults, using a similar exercise protocol to this study [11]. This group found an increase of $0.066 \mathrm{~L} \mathrm{O}_{2}$ * $\mathrm{min}^{-1}$ between the first and second GXT, and an increase of 0.030 $\mathrm{LO}_{2}{ }^{*} \min ^{-1}$ between the second and third GXT (although only the first and third were statistically different). Interestingly, the magnitude of the change in $\mathrm{VO}_{2}$ max between the first and second GXT is almost identical to the statistically significant increase of 0.064 $\mathrm{LO}_{2}{ }^{*} \mathrm{~min}^{-1}$ that we found in the current work. Although this increase in $\mathrm{VO}_{2}$ max was statistically significant, the small magnitude of this change $(<2 \%)$ is likely not of practical significance and did not have an effect on our conclusions. However, this finding is important because it helps to quantify the magnitude of the learning effect during graded exercise tests on $\mathrm{VO}_{2}$ max.

One limitation of this study is that despite the relatively large sample size, it is still possible that $\mathrm{S}_{\mathrm{a}} \mathrm{O}_{2}$ explains a small but significant portion of the variability in the relationship between $\mathrm{tHb}$ and $\mathrm{VO}_{2}$ max that we were underpowered to detect. Another limitation of this study is that we did not directly measure arterial oxygen saturation or oxygen content. Although pulse oximetry has previously been shown to reliably measure $\mathrm{S}_{\mathrm{a}} \mathrm{O}_{2}$ during exercise [37], direct measurements of arterial blood gas, $\mathrm{pH}$, and temperature during exercise could lead to further insights on this topic. Finally, it is difficult to determine causal relationships when looking at cross-sectional data. An additional factor that may influence the relationship between $\mathrm{tHb}$ and $\mathrm{VO}_{2}$ max is maximal cardiac output, and future research is therefore required on this subject.

\section{Conclusions}

At moderate altitude, over $90 \%$ of endurance-trained males and females experienced EIAD. Despite a wide range of exercise-induced desaturation values, taking into account $\mathrm{S}_{\mathrm{a}} \mathrm{O}_{2}$ at $\mathrm{VO}_{2}$ max did not improve the relationship between $\mathrm{tHb}$ and $\mathrm{VO}_{2}$ max at moderate altitude. This finding may be in part due to a relationship between oxyhemoglobin desaturation during exercise and tHb, which warrants further investigation. Future research is required determine how other physiological parameters, such as cardiac output, influence the relationship between $\mathrm{tHb}$ and $\mathrm{VO}_{2}$ max.

\section{Acknowledgements}

This study was funded in part by a Student Research Award from the Rocky Mountain Chapter of the American College of Sports Medicine, as well as a University of Colorado Beverly Sears Graduate Student Grant. The authors would like to thank Dillon Frisco and Peter Kim for their assistance with this study.

\section{Conflicts of interest}

The authors declare that they have no conflict of interest.

\section{References}

[1] Bassett DR, Howley ET. Limiting factors for maximum oxygen uptake and determinants of endurance performance. Med Sci Sports Exerc 2000; 32: 70-84

[2] Brocherie F, Millet GP, Hauser A, Steiner T, Rysman J, Wehrlin JP, Girard O. "Live high-train low and high" hypoxic training improves team-sport performance. Med Sci Sports Exerc 2015; 47(10): 2140-2149

[3] Brothers MD, Hilger K, Carson JM, Sullivan L, Byrnes WC. GXT responses in altitude-acclimatized cyclists during sea-level simulation. Med Sci Sports Exerc 2007; 39: 1727-1735

[4] Buchfuhrer MJ, Hansen JE, Robinson TE, Sue DY, Wasserman K, Whipp B]. Optimizing the exercise protocol for cardiopulmonary assessment. J Appl Physiol 1983; 55: 1558-1564

[5] Dempsey J, Amann M, Harms C, Wetter T. Respiratory system limitations to performance in the healthy athlete: Some answers, more questions!. Dtsch Z Für Sportmed 2012; 157-162

[6] Dempsey JA, Hanson PG, Henderson KS. Exercise-induced arterial hypoxaemia in healthy human subjects at sea level. J Physiol 1984; 355: 161-175

[7] Dempsey JA, Wagner PD. Exercise-induced arterial hypoxemia. J Appl Physiol 1999; 87: 1997-2006

[8] Dominelli PB, Foster GE, Dominelli GS, Henderson WR, Koehle MS, McKenzie DC, Sheel AW. Exercise-induced arterial hypoxaemia and the mechanics of breathing in healthy young women: Hypoxaemia and ventilatory mechanics in exercising women. J Physiol 2013; 591: 3017-3034 
[9] Dominelli PB, Render JN, Molgat-Seon Y, Foster GE, Romer LM, Sheel AW. Oxygen cost of exercise hyperpnoea is greater in women compared with men. J Physiol 2015; 593: 1965-1979

[10] Dunn A, Lo V, Donnelly S. The role of the kidney in blood volume regulation: The kidney as a regulator of the hematocrit. Am J Med Sci 2007; 334: 65-71

[11] Edgett BA, Bonafiglia JT, Raleigh JP, Rotundo MP, Giles MD, Whittall JP, Gurd BJ. Reproducibility of peak oxygen consumption and the impact of test variability on classification of individual training responses in young recreationally active adults. Clin Physiol Funct Imaging 2017; 38: 630-638

[12] Gaston A-F, Durand F, Roca E, Doucende G, Hapkova I, Subirats E. Exercise-induced hypoxaemia developed at sea level influences responses to exercise at moderate altitude. PLoS One 2016; 11: e0161819

[13] Gore C], Sharpe K, Garvican-Lewis LA, Saunders PU, Humberstone CE, Robertson EY, Wachsmuth NB, Clark SA, McLean BD, Friedmann-Bette B, Neya M, Pottgiesser T, Schumacher YO, Schmidt WF. Altitude training and haemoglobin mass from the optimised carbon monoxide rebreathing method determined by a meta-analysis. Br J Sports Med 2013; 47: i31-i39

[14] Guenette JA, Witt JD, McKenzie DC, Road JD, Sheel AW. Respiratory mechanics during exercise in endurance-trained men and women. J Physiol 2007; 581: 1309-1322

[15] Harms CA, McClaran SR, Nickele GA, Pegelow DF, Nelson WB, Dempsey JA. Effect of exercise-induced arterial $\mathrm{O} 2$ desaturation on VO2max in women. Med Sci Sports Exerc 2000; 32: 1101-1108

[16] Harriss DJ, Macsween A, Atkinson G. Standards for ethics in sport and exercise science research: 2018 update. Int J Sports Med 2017; 38: 1126-1131

[17] Hopkins WG. Measures of reliability in sports medicine and science. Sports Med 2000; 30: 1-15

[18] Horwitz LD, Lindenfeld J. Effects of enhanced ventricular filling on cardiac pump performance in exercising dogs. J Appl Physiol 1985; 59: 1886-1890

[19] Joyner MJ. Physiological limits to endurance exercise performance: influence of sex. J Physiol 2017; 595: 2949-2954

[20] Joyner M], Coyle EF. Endurance exercise performance: The physiology of champions. J Physiol 2008; 586: 35-44

[21] Krip B, Gledhill N, Jamnik V, Warburton D. Effect of alterations in blood volume on cardiac function during maximal exercise. Med Sci Sports Exerc 1997; 29: 1469-1476

[22] Lawler J, Powers SK, Thompson D. Linear relationship between VO2max and VO2max decrement during exposure to acute hypoxia. J Appl Physiol 1988; 64: 1486-1492
[23] Lundby C, Montero D, Joyner M. Biology of VO2 max: looking under the physiology lamp. Acta Physiol 2016 Available from: http://doi. wiley.com/10.1111/apha.12827

[24] Lundby C, Robach P. Performance enhancement: What are the physiological limits? Physiology 2015; 30: 282-292

[25] Powers SK, Martin D, Cicale M, Collop N, Huang D, Criswell D. Exercise-induced hypoxemia in athletes: Role of inadequate hyperventilation. Eur J Appl Physiol 1988; 58: 298-302

[26] Powers SK, Dodd S, Lawler J, Landry G, Kirtley M, McKnight T, Grinton S. Incidence of exercise-induced hypoxemia in elite endurance athletes at sea level. Eur J Appl Physiol 1992; 65: 37-42

[27] Prommer N, Schmidt W. Loss of CO from the intravascular bed and its impact on the optimised CO-rebreathing method. Eur J Appl Physiol 2007; 100: 383-391

[28] Prommer N, Thoma S, Quecke L, Gutekunst T, VöLzke C, Wachsmuth N, Niess AM, Schmidt W. Total hemoglobin mass and blood volume of elite Kenyan runners. Med Sci Sports Exerc 2010; 42: 791-797

[29] Roberts D, Smith DJ. Erythropoietin concentration and arterial haemoglobin saturation with supramaximal exercise. J Sports Sci 1999; 17: 485-493

[30] Roberts D, Smith D], Donnelly S, Simard S. Plasma-volume contraction and exercise-induced hypoxaemia modulate erythropoietin production in healthy humans. Clin Sci 2000; 98: 39-45

[31] Rowell LB, Taylor HL, Wang Y, Carlson WS. Saturation of arterial blood with oxygen during maximal exercise. J Appl Physiol 1964; 19: 284-286

[32] Ryan B], Goodrich JA, Schmidt W, Kane LA, Byrnes WC. Ten days of intermittent, low-dose carbon monoxide inhalation does not significantly alter hemoglobin mass, aerobic performance predictors, or peak-power exercise tolerance. Int J Sports Med 2016; 37: 884-889

[33] Ryan B], Goodrich JA, Schmidt WF, Stothard ER, Wright KP, Byrnes WC. Haemoglobin mass alterations in healthy humans following four-day head-down tilt bed rest. Exp Physiol 2016; 101: 628-40

[34] Schmidt W, Prommer N. The optimised CO-rebreathing method: A new tool to determine total haemoglobin mass routinely. Eur J Appl Physiol 2005; 95: 486-495

[35] Schmidt W, Prommer N. Impact of alterations in total hemoglobin mass on VO2max. Exerc Sport Sci Rev 2010; 38: 68-75

[36] Scroop GC, Shipp NJ. Exercise-induced hypoxemia: Fact or fallacy? Med Sci Sports Exerc 2010; 42: 120-126

[37] Yamaya Y, Bogaard HJ, Wagner PD, Niizeki K, Hopkins SR. Validity of pulse oximetry during maximal exercise in normoxia, hypoxia, and hyperoxia. J Appl Physiol 2002; 92: 162-168 